\title{
Calling all doctorpreneurs
}

\author{
Fiona Godlee editor in chief
}

The BMJ

How much do you love or hate the tools and systems you work with every day? If you hate them, do you have the energy or skills to invent new ones? A growing number of "doctorpreneurs" are finding that they do, and, as Anne Gulland reports (doi:10.1136/bmj.k685), the NHS is supporting innovations that offer better quality of care at less cost.

Innovations range from apps that help patients quit smoking, through administrative aids for GP locums, to entire back-office systems for frontline doctors. And it's not only about IT: there are new instruments, such as episiotomy scissors, and new models of care. Elsewhere in the journal, radiologist Giles Maskell ponders an innovation in practice: the replacement of plain chest radiography with CT pulmonary angiography in routine assessment of acutely ill patients (doi:10.1136/bmj. k769). Maskell acknowledges concerns about overdiagnosis—raised in a previous BMJ article (doi:10.1136/ bmj.f3368)—increased radiation doses, and the challenge of training for and resourcing such a shift. But the limitations of plain chest radiography are obvious, and this development is one to watch.

We've introduced an innovation of our own: authors' perspectives on their research (http://blogs.bmj.com/bmj/ category/authors-perspective). Our aim is to provide insights into a researcher's career path, how a particular research idea emerged, how practical challenges such as funding, ethics approval, and recruitment were overcome, and what lessons were learnt along the way. This week's perspective, by Laurie Tomlinson, also carries a plea: to preserve patients' trust in the use of their anonymised data for clinical research.

Tomlinson and her colleagues wanted to investigate concerns about hyperkalaemia and acute kidney injury in older people with urinary tract infection who are given trimethoprim. They used the ability - perhaps unique to the UK — to link anonymised primary care and hospital admission data. Their large national cohort study (doi:10.1136/bmj.k341) adjusted for confounders but was also able to isolate trimethoprim from co-trimoxazole and to look at patients who weren't also taking renin-angiotensin system blockers. They found that, compared with other antibiotics, trimethoprim was associated with a greater risk of acute kidney injury and hyperkalaemia. "Public confidence in the use of such data may be falling," says Tomlinson.

"Hopefully, examples of research where careful use of these vitally important resources leads directly to guidance to improve healthcare will maintain the trust of our patients."

\section{Follow Fiona on Twitter @fgodlee}

Published by the BMJ Publishing Group Limited. For permission to use (where not already granted under a licence) please go to http://group.bmj.com/group/rights-licensing/ permissions 